\title{
A Survey Study of Public Health Nurses' Knowledge in Disaster Management in Indonesia
}

\author{
Ardia Putra $^{1 * \mathbb{D}}$, Wongchan Petpichetchian ${ }^{2}$, Khomapak Maneewat $^{2}$ (D) \\ ${ }^{1}$ Department of Nursing Management, Faculty of Nursing, Universitas Syiah Kuala, Banda Aceh, Indonesia; ${ }^{2}$ Department of \\ Surgical Nursing, Faculty of Nursing, Prince of Songkla University, Hat Yai, Thailand
}

\section{Abstract}

Edited by: Mirko Spirosk Citation: Putra A, Petpichetchian W, Maneewat K. A Survey Study of Public Health Nurses' Knowledge in Disaster Management in Indonesia. Open Access Maced $J$ Med Sci. 2021 Dec 23; 9(G):328-336 https://doi.org/10.3889/oamjms.2021.7839 Keywords: Disaster; Knowledge; Preparedness; *Correspondence: Ardia Putra, Department Correspondence: Arda Putra, Department of Nursing Bagent, Faculty of Nursing, Universtas Syiah Kuala, Received: 06-Nov-2021 Revised: 03-Dec-2021 Accepted: 16-Dec-2021 Copyright: @ 2021 Ardia Putra Wongchan Petpichetchian, Khomapak Maneewa Funding: This study was supported by Graduate School, Prince of Songkla University, Thailand and Rockefeller Competing Interests: The authors have declared tation competing interests exis Open Access: This is an open-access article distributed under the terms of the Creative Commons AtributiononCommercial 4.0 International License (CC BY-NC 4.0)

\begin{abstract}
AIM: This descriptive survey study examines the level of Public Health Nurses' (PHNs) knowledge regarding disaster management. The knowledge was examined according to three disaster phases, including preparedness, response and recovery phase.

MATERIALS AND METHODS: A stratified proportionate random sampling method recruited 252 PHNs of Aceh Province, Indonesia. The data were collected by using the questionnaire developed by the researchers. They were analyzed using frequencies, percentages, means, standard deviations, and minimum and maximum scores. Additional analyses were performed to identify potential contributing factors to the PHNs' knowledge using the Spearman rank correlation $\left(r_{s}\right)$ and the Mann-Whitney $\mathrm{U}$ test.

RESULTS: The finding showed that PHNs' knowledge in disaster management was moderate $(\mathrm{M}=70.73 \%, \mathrm{SD}=$ $8.41)$, and nearly half of the subjects $(42.5 \%)$ were categorized in this level. The lowest mean score was found in the response phase $(64.75 \%)$, and four items with the lowest percentage of correct answers were also found in this phase. CONCLUSION: The low level of knowledge for the response phase can be used to flag health policymakers and public health centers to develop appropriate educational training and disaster drills for PHNs in collaboration with
\end{abstract} stakeholders in the community.

\section{Introduction}

A disaster can be defined as the most significant catastrophe from natural or human activities, which can cause human suffering and generate the complexity of human needs that survivors cannot fulfill by themselves [1]. Recently, the frequency of disasters has been increasing worldwide, and over the past 30 years, millions of lives have been lost due to disasters [2].

Indonesia is considered a high risk of natural disasters, such as floods, earthquakes, etc. Among the provinces of Indonesia, Aceh province is at the most significant risk of natural disasters such as earthquakes and landslides because most districts and cities in Aceh are located at the boundary of a tectonic plate and earth fault [3]. The worst disaster in Aceh was the earthquake on December 26, 2004, followed by the tsunami, which hit six countries in Asia and Africa [1]. More recently, a 7.7 magnitude earthquake occurred on April 7, 2010, in a coastal area of Aceh in northwestern Indonesia [4]. This situation signifies that Aceh should develop a plan for natural disaster management, and it needs supports of several professionals, including nurses [5].
Nurses are responsible for helping people during and after a disaster [6]. With this regard, nurses should have the appropriate knowledge to fulfill the essential activities necessary when they are involved in disaster management.

Furthermore, since disasters affect people's health and the public healthcare system, Public Health Nurses'(PHNs) have a significant role in managing and assisting in all disaster phases [1], including preparedness, response, and recovery. Training PHNs for involvement in all these phases is recommended as a part of a comprehensive disaster management strategy [7], [8]. To provide successful health system responses and continuous care delivery in disaster situations and lessen the harmful effects of potential disasters, PHNs should possess specific related knowledge within the scope of their responsibility and their contribution in disaster management for future disasters [9].

At present, there is no known report in Indonesia, mainly Aceh province, to what levels $\mathrm{PHNs}$ have possessed knowledge regarding disaster management. Therefore, this study examined PHN knowledge of disaster management in Aceh, Indonesia. 


\section{Materials and Methods}

\section{Study design and sampling}

A descriptive survey was used in this study. The conceptual framework was constructed based on the work of Polivka et al. [7], Jennings-Sanders [10], and the three existing guidelines from Manitoba Health, $\mathrm{WHO}$, and Rogers and others as cited in Rogers and Lawhorn [8], [11], [12]. Polivka's three phases and Jennings-Sanders's four phases of disaster management were combined into only three phases, namely, preparedness, response, and recovery. The existing guidelines were integrated for each phase to address the knowledge PHNs explicitly acquire to respond to disasters.

PHNs who worked in 309 Public Health Centers (PHCs) in Aceh Province, Indonesia, were targeted from the total population of 2292 PHNs [13]. Singchangchai et al. [14] reported that if the population size is between 1000 and 9999, approximately $10 \%$ of the subjects can represent the population. In this regard, $229 \mathrm{PHNs}$ working at $\mathrm{PHCs}$ in Aceh were recruited. Then, $10 \%$ of subjects were added to overcome unresponsive samples. Thus, 252 subjects were recruited. The subjects were drawn using stratified proportionate random sampling. The location of PHCs: urban and suburban/rural areas were stratified, and $50 \%$ of them were randomly selected. PHNs working at the selected PHCs with at least one year of working experience in the community were listed. Then, the proportionate numbers of PHNs worked at each PHC were subsequently drawn using a lottery.

\section{Instruments}

The PHN' Knowledge Regarding Disaster Management Questionnaire (PHNK-DMQ) was distributed by the researchers to the selected PHNs and asked them to complete it. 36 True/ False questions were divided into three dimensions: preparedness, response, and recovery phases. A score of 0 or 1 was given for incorrect and correct answers, respectively. A total score was a summed score of all correct answers and varied from 0 to 36. The knowledge scores were transformed to be percentages to be easy for interpretation using educational standards. Higher scores indicated a higher level of knowledge. For interpretation, the researcher divided the transformed scores into four levels consists of: $<21.6$ (Needs Improvement), 21.6-25.1 (Low), 25.2-28.7 (Moderate), and >28.8 (High) [15]. It was content validated by three experts. The internal consistency reliability was assessed with 20 subjects with similar criteria to the study subjects, and the Kuder-Richardson 20 coefficient of 0.70 was considered adequate [16].

Table 1: Frequency and percentage of demographic data of the subjects $(n=252)$

\begin{tabular}{|c|c|c|}
\hline Characteristic & Frequency & Percentage \\
\hline \multicolumn{3}{|l|}{ PHNs' working area } \\
\hline Urban & 149 & 59.1 \\
\hline Suburban/Rural & 103 & 40.9 \\
\hline \multicolumn{3}{|c|}{ Age (years) (Min-Max $=20-55, M=30 \pm 6$ ) } \\
\hline$<3$ & 154 & 61.1 \\
\hline $30-40$ & 87 & 34.5 \\
\hline$>40$ & 11 & 4.4 \\
\hline \multicolumn{3}{|l|}{ Gender } \\
\hline Male & 51 & 20.2 \\
\hline Female & 201 & 79.8 \\
\hline \multicolumn{3}{|l|}{ Marital status } \\
\hline Single & 68 & 27.0 \\
\hline Married & 176 & 69.8 \\
\hline Widowed/Divorced & 8 & 2.2 \\
\hline \multicolumn{3}{|c|}{ Working experience as a PHN (years) } \\
\hline \multicolumn{3}{|c|}{$($ Min-Max $=1-32, M=7.2 \pm 5.7)$} \\
\hline$<5$ & 106 & 42.1 \\
\hline $5-10$ & 95 & 37.7 \\
\hline$>10$ & 51 & 20.2 \\
\hline \multicolumn{3}{|c|}{ Highest level of nursing education } \\
\hline Diploma & 226 & 89.7 \\
\hline Bachelor's & 26 & 10.3 \\
\hline \multicolumn{3}{|c|}{ Experience in assisting disaster victims } \\
\hline Yes & 113 & 44.8 \\
\hline No & 139 & 55.2 \\
\hline \multicolumn{3}{|c|}{ Attending training and education } \\
\hline Yes & 114 & 45.2 \\
\hline No & 138 & 54.8 \\
\hline \multicolumn{3}{|c|}{ The method used in developing knowledge } \\
\hline \multicolumn{3}{|c|}{ Reading books and materials related to disasters } \\
\hline Never & 27 & 10.7 \\
\hline Sometimes & 188 & 74.6 \\
\hline Often & 37 & 14.7 \\
\hline \multicolumn{3}{|c|}{ Searching for disaster-related material on the Internet } \\
\hline Never & 93 & 36.5 \\
\hline Sometimes & 134 & 53.2 \\
\hline Often & 25 & 9.9 \\
\hline \multicolumn{3}{|c|}{ Attending seminars and conferences related to disasters } \\
\hline Never & 119 & 47.2 \\
\hline Sometimes & 125 & 49.6 \\
\hline Often & 8 & 3.2 \\
\hline
\end{tabular}

\section{Ethical considerations}

Approval from the Institutional Review Board of Faculty of Nursing, Prince of Songkla University, Thailand, was obtained. Permission from the head of the Health Department at the province and districts level was requested. Furthermore, from the head of PHCs. Then, eligible subjects were informed about their right to withdraw from this study for any reason without any fear or negative consequences. After the subjects agreed to participate, they were asked to fill up the demographic data form and respond to the PHNK-DMQ.

\section{Statistical analysis}

The survey data were captured and analyzed using SPSS v.19. Descriptive statistics, including frequencies, percentages, means, and standard deviations, were used to analyze the data. Then, the scores for the factors related to the PHN' knowledge were examined by using the Spearman rank correlation $\left(r_{s}\right)$ and the Mann-Whitney $\mathrm{U}$ test. 


\section{Results}

The response rate was $100 \%$. Subjects were obtained from 27 PHCs in eleven districts and municipalities of Aceh Province. More than half of the subjects worked in urban areas $(59.1 \%)$, most of them were less than 30 years old $(61.1 \%)$, with the mean age being 30 years old. The majority were female $(79.8 \%)$, and around three-fourths of them were married (69.8\%). Nearly half of the subjects $(42.1 \%)$ had been working as PHNs for less than five years; the mean was 7.25 years, and most of them had a diploma level of education $(89.7 \%)$. More than half of the subjects did not have direct experience assisting disaster victims (55.2\%) and never received any specific disaster training or education (54.8\%). The methods used by the PHNs in developing their knowledge regarding disaster management included reading books and other materials $(74.6 \%)$, using the Internet (53.2\%), and attending related seminars and conferences (49.6\%) (Table 1).

Table 2: Mean, SD, Min-Max, and the level of PHNs' knowledge ( $n=252$ )

\begin{tabular}{lllll}
\hline Knowledge of each disaster phase & $\mathrm{M}(\%)$ & $\mathrm{SD}$ & Min-Max $(\%)$ & Level \\
\hline Preparedness $(10$ items) & 76.23 & 13.76 & $20-100$ & Moderate \\
Response (18 items) & 64.75 & 9.66 & $33.33-88.89$ & Low \\
Recovery $(8$ items) & 77.33 & 12.13 & $37.5-100$ & Moderate \\
Total (36 items) & 70.73 & 8.41 & $36.11-94.44$ & Moderate \\
\hline
\end{tabular}

The total score for the PHNs' knowledge was at a moderate level $(70.73 \%, S D=8.41)$ (Table 2), and nearly half of the subjects $(42.5 \%)$ had a moderate level of knowledge. In addition, item analysis was performed to determine the number of subjects who correctly answered each question (Table 3).

\section{Discussion}

The PHNs participating in this study possessed a moderate level of knowledge of disaster management. The PHNs had the highest knowledge of the recovery phase, followed by the preparedness and response phases (Table 2). This finding is not surprising. Generally, the basic nursing education in Indonesia does not equip nurses with exceptional knowledge of disaster management. Based on the first author's personal experiences in teaching at a nursing institution in Aceh province, it was revealed that only two teaching hours were allocated for content related to disasters in both the diploma program and the bachelor's degree program.

Furthermore, this subject was only taught in a classroom setting and only entailed a general overview of disaster nursing management. Even in the US, where disaster events are frequent, the time allocated for disaster-related content is inadequate. A 2003 survey of 2013 schools of nursing in the US with 348 respondents revealed that only $53 \%$ of the schools offered content in disaster preparedness, and a mean of four hours was devoted to this content. In general, nursing school faculties were inadequately prepared to teach disaster preparedness content [17].

Among the three areas of knowledge relating to the disaster phases, nurses achieved the highest mean score for their knowledge of the recovery and preparedness phases. Although on average, the scores for the preparedness and recovery phases were at a moderate level, the item analysis revealed that there were certain areas of questions that $93-98 \%$ of the subjects could answer correctly (Table 3). The item that the highest number of PHNs answered correctly was "recognizing the emergency route." This may be because the subjects had been working in their communities for some time already. They were familiar with the geographic structure and the routes of evacuation. According to Jakeway et al., specific knowledge concerning the assessment of the evacuation route is very important. The knowledge was included the agency's emergency response plan, the plan's location, how to access it, and how to keep informed of any revised plans for the PHNs [9]. This knowledge then provides the basis for developing effective disaster planning [18], [19] for evacuating communities, particularly vulnerable populations (i.e., the elderly, people with physical impairments, and people with mental health conditions) [1], [20], [21].

Two other areas that a high number of PHNs $(95 \%)$ knew about were "the prevention and delimiting of the transmission of infectious diseases" and "the

Table 3: The five items with the highest and lowest percentages of correct answers $(n=252)$

\begin{tabular}{|c|c|c|c|}
\hline Item & Knowledge of PHNs & $\mathrm{n}$ & $\%$ \\
\hline \multicolumn{4}{|c|}{ The five items with the highest percentage of correct answers } \\
\hline 1 & $\begin{array}{l}\text { Recognizing the emergency route for the community and directly informing } \\
\text { the people about it }\end{array}$ & 247 & 98 \\
\hline 36 & $\begin{array}{l}\text { Prevention and delimiting of the transmission of infectious diseases among } \\
\text { a sheltered population }\end{array}$ & 240 & 95 \\
\hline 4 & $\begin{array}{l}\text { Responsibility to conduct case investigations and provide public health } \\
\text { information regarding a disease outbreak }\end{array}$ & 239 & 95 \\
\hline 30 & The major cause of diarrhea following a natural disaster & 237 & 94 \\
\hline 5 & $\begin{array}{l}\text { Participating in disaster drills and training that are specific to the PHN's } \\
\text { geographical area }\end{array}$ & 235 & 93 \\
\hline \multicolumn{4}{|c|}{ The five items with the lowest percentage of correct answers } \\
\hline 18 & Basic Life Support (BLS) & 44 & 17 \\
\hline 14 & Principles of disaster triage & 52 & 21 \\
\hline 16 & Sorting and screening disaster victims & 54 & 21 \\
\hline 26 & Vaccination routes & 63 & 25 \\
\hline 33 & Strategies to increase community disaster awareness after a disaster & 66 & 26 \\
\hline
\end{tabular}


responsibility to conduct case investigations and provide public health information regarding disease outbreaks." The prevention and delimiting of the transmission of infectious diseases are nowadays considered to be a "basic" type of nursing knowledge for which most nurses have been prepared and which they use in their routine work. Relevantly, because diseases are a contributing factor during a disaster event, the Association of State and Territorial Directors of Nursing noted that PHNs must be competent in epidemiological surveillance and investigating infectious diseases [22]. Surveillance helps gain important data regarding disaster victims to utilize healthcare staff and equipment most appropriately [23]. A study conducted by Rogers and Lawhorn also indicated that nearly half of respondents (48\%) felt unsure of their roles and responsibilities for providing health surveillance during a hurricane disaster [8].

It is not surprising that knowledge of the response phase received the lowest mean score (Table 2). Knowledge of this phase is considered situation-specific. It involves unique, comprehensive content. Item analysis findings (Table 3 ) support that this is precise knowledge. Only $17 \%$ and $21 \%$ of the subjects in this study correctly answered the basic life support question and the principles of disaster triage, respectively. It was followed by knowledge of disaster triage (item 16) and vaccinations (item 26). The low level of knowledge the PHNs had regarding the response phase should be brought to the attention of the authorities, as PHNs hold significant roles and responsibilities for assisting their communities, particularly during the response phase [1]. Therefore, $\mathrm{PHNs}$ should understand the scope and definition of their responsibilities and roles in responding to disaster impacts [9]. During the response phase, nursing care aims to minimize the health hazards and life threats caused by a disaster [24] and diminish its negative consequences for the people's health and the public healthcare service [1]. Consequently, the insufficient knowledge of the subjects regarding this phase may cause them uncertainty in responding during disaster occurrences.

A careful examination of why so few subjects in this study correctly answered the "Basic Life Support" question revealed a few explanations. First, the number of subjects who attended BLS training was relatively low $(29 \%)$. Thus, it can be assumed that a lack of BLS training can negatively impact a subject's knowledge of disaster response. Since BLS is an essential life-saving technique for use with all disaster victims, its use is expected to result in better outcomes for survivors [25]. Thus, PHNs must know this technique [26]. Secondly, the findings must be interpreted with caution due to the nature of the questionnaire itself. The BLS question asked, "Basic life support (BLS) includes stopping bleeding, cardioversion, and breathing support." The majority of the subjects who checked "True" for this statement (the correct answer is "False") may not have read the statement carefully and assumed that "cardioversion" was similar to cardiac massage.

The small number (less than one-fourth) of PHNs who possessed knowledge of disaster triage (items 14 and 16, Table 3) has implications for the future work of PHNs. During a disaster event, PHNs need to use this knowledge to deliver appropriate care to injured victims to save as many lives as possible [27]. Similarly, a study conducted by Mitani and others found that approximately one-third of nurses were unfamiliar with disaster triage principles, and $40 \%$ of them did not understand the techniques involved [27]. Their limited knowledge in this area might result from the subjects' misconceptions about the concepts of daily triage and disaster triage [2].

For the response phase, item 26 (route of vaccinations) was an item that few subjects got correct (25\%). It might be because the majority of the subjects had a nursing diploma (89\%). Similarly, a study conducted by De Felice et al. revealed that different levels of education (diplomas, practicing nurses, and post-graduate degrees) possibly resulted in differences in nurses' understanding of the transmitted smallpox and $Y$. pestis viruses and the method of their transport [28]. Therefore, it is recommended that $\mathrm{PHNs}$ improve their knowledge and practices regarding immunizations and vaccinations. Furthermore, there must be collaborative learning among PHNs and other professionals to update their knowledge regarding the advantages, barriers, benefits, and risks of vaccinations and immunizations [29].

In addition, the low to moderate level of knowledge that the PHNs in this study had may be associated with their lack of self-directed learning regarding disaster management. As mentioned previously, about 3-15\% of the subjects "often" attended seminars and conferences and studied disaster-related materials (either by accessing them on the Internet or reading books) (Table 1 ). Similarly, a study to examine the knowledge and perceived skill of PHNs in tsunamiaffected and non-affected areas found that many nurses working in PHCs lacked self-preparedness for improving their knowledge regarding tsunami disaster nursing [30]. Accordingly, most nurses (60\%) in Indonesia have few opportunities to attend training to prepare for their professional roles and competencies, in general [31]. Consequently, their insufficiency of specific knowledge regarding disaster management will contribute to their lack of ability to respond during disaster events [32]. Thus, it is highly recommended that PHNs improve their knowledge of disaster competencies [33] to develop their preparedness for future disaster events [34].

Overall, the subjects' working areas, work experience as $\mathrm{PHNs}$, inadequate previous disaster experience, educational backgrounds, and lack of disaster training and education may also have contributed to their moderate level of knowledge, as found in this study. In order to support this prediction, these factors were examined for their relationship 
with the PHNs' knowledge scores. The only working experience was found to have a statistically significant relationship with the PHNs' knowledge. The other factors were insignificant but indicated a positive trend between greater working experience, higher nursing education, and more training and education on the one hand, and a higher level of knowledge on the other hand. In contrast, nurses with little disaster experience who worked in suburban or rural areas had higher levels of knowledge. These findings can be explained as follows.

This study found that working experience was positively correlated with professional competencies, including knowledge, for the PHNs in Aceh. As seen, nearly half of the subjects had less than five years of work experience as PHNs (42.1\%). Although the strength of the relationship between working experience and knowledge was relatively low (Figure 1), this factor is still associated with the moderate level of knowledge among Acehnese PHNs. A study conducted by Maulidar found that more than half of nurses $(52.3 \%)$ who had less than five years of working experience had limited knowledge regarding disaster nursing management [30]. It was also found that the duration of experience in clinical nursing practice positively influenced the nurses' knowledge, in general [35], [36]. It was found that the nurses with a lot of work experience improved their knowledge, skills, and attitudes more than those with little work experience. Therefore, prior nursing experience in clinical practice contributed to the development of adequate knowledge and capabilities in nurses [35].

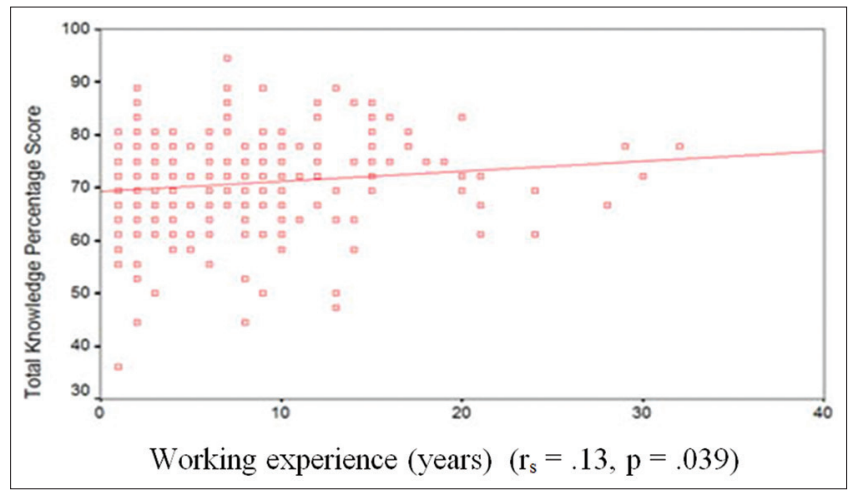

Figure 1: Scatter plot between working experience and Public Health Nurses' knowledge (Spearman Rank Correlation)

Duration of professional experience was strongly correlated with the level of knowledge [37], [38]. The basic knowledge derived from a nurse's individual experience could be applied during a disaster event, improving that nurse's confidence in facing disasters. Therefore, providing care to patients in everyday clinical practice will provide the basis for enhancing the PHNs' knowledge and ability to identify any potential health problems when responding to a disaster event [39].

Surprisingly, the findings from this study revealed that the subjects who had previous experience with disasters seemed to have lower knowledge scores, although this difference was not significant (Figure 2). It may be due to the low number of experienced subjects who participated in this study. As addressed previously, only 113 of the subjects $(44.8 \%)$ had experience assisting disaster victims. Nearly half of these (47.8\%) had experienced only one disaster event, usually either a tsunami $(47.4 \%)$ or a flood $(35 \%)$. As noted in a previous study conducted by Duong, previous disaster event experience is vital for PHNs to improve their awareness regarding disaster competencies and enhance their confidence in providing aid in disaster events. However, in this study, only $37 \%$ of the participants reported their involvement in disaster response [40]. Similarly, Hammad et al. also stated that previous involvement in disaster response was valuable for enhancing nurses' knowledge and reducing their feelings of inadequacy and fear [33].

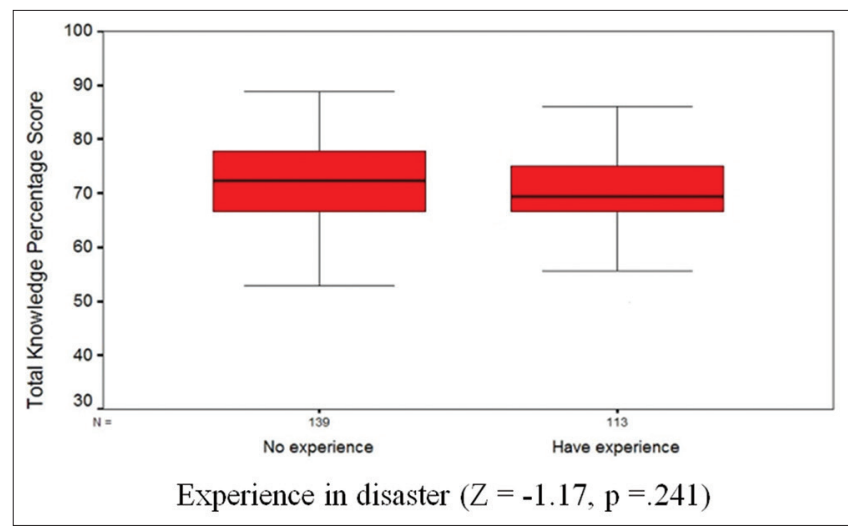

Figure 2: Box plot between experience in disaster and public health nurses' knowledge (Mann-Whitney $U$ test)

The different levels of nursing education attained by the subjects also contributed to their different levels of knowledge regarding disaster management. Although this difference was not statistically significant, the bachelor's degree nurses had a higher knowledge regarding disaster management than the diploma nurses (Figure 3). In the past, approximately $39 \%$ of Indonesian nurses were diploma nurses, $1 \%$ were degree nurses (bachelor's), and the rest were educated at the secondary school level (SPK) [41]. Accordingly, the majority of the subjects in this study possessed a nursing diploma (89.7\%). Previous studies regarding

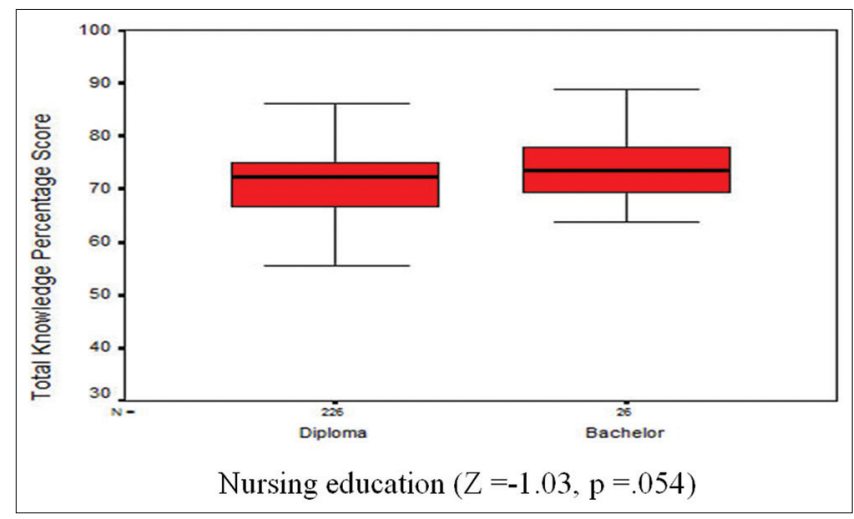

Figure 3: Box plot between nursing education and public health nurses' Knowledge (Mann-Whitney U-test) 
nursing education in Indonesia revealed that diploma nurses possessed inadequate knowledge and skills [30], [31], [42].

Although the minimum level of nursing education in Indonesia was upgraded to the diploma level in 1997 [43], this may not have improved nurses' knowledge in all aspects. Notably, the topic of disaster nursing is still not integrated into diploma nursing curricula in Indonesia [44], even in the bachelor's degree nursing curricula [45]. In addition, the AIPNI has made recommendations to add specific subjects into the nursing curriculum of each province. Because Aceh is a high-risk province with the potential of experiencing annual natural disasters, this province should pioneer in developing disaster nursing education in Indonesia [46]. This finding implies that there should be further investigations into the feasibility of offering disaster-related classes at nursing schools in Indonesia, particularly in Aceh province. The amount of time to be dedicated to them should also be investigated. Unlike Indonesia, other high-risk nations such as Japan have already integrated disaster subjects into their nursing curricula [47]. Thus, adding more disaster-related content to the basic nursing education program is recommended. It will better improve the capability of nurses in disaster management.

Consequently, well-educated nurses in disaster nursing management will gain confidence and an understanding of disaster plans and equipment, minimize victim morbidity and mortality rates, and improve community health status and reduce disaster-related costs [10], [48]. In addition, the advancement of knowledge regarding disaster management helps reduce the suffering of disaster victims. However, it can also be used for assisting regular patients in everyday practice at PHCs.

As mentioned previously, more than half of the subjects $(54.8 \%)$ in this study had not attended any training or education related to disasters. Similarly, the previous studies that explored the importance of training and education for nurses noted that nurses lacked knowledge regarding disaster management [49], [50]. Although the additional analysis did not reveal a significant difference (Figure 4), there was a positive relationship between training experience

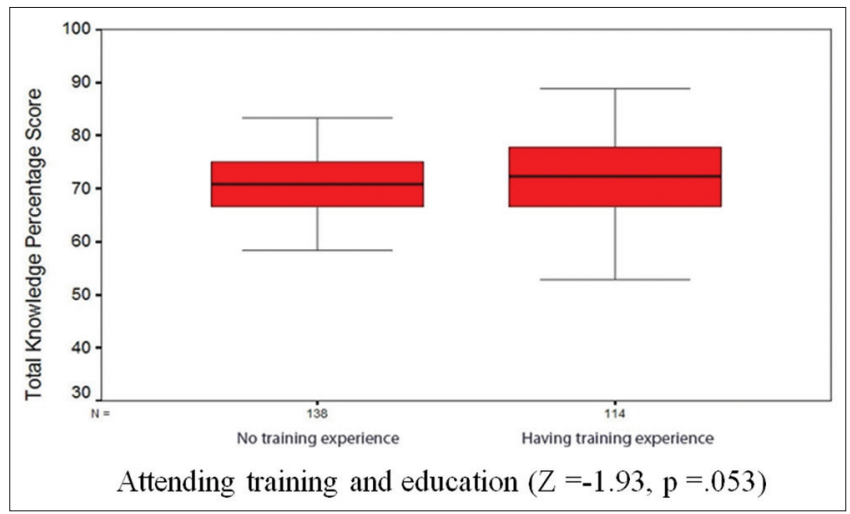

Figure 4: Box plot between attending training and education and public health nurses' knowledge (Mann-Whitney U-test) and knowledge of disaster management. Since most of the PHNs in this study was educated at the diploma level and had minimal experience assisting disaster victims, additional training and education regarding disasters are necessary for PHNs.

PHC administrators should provide appropriate public educational programs regarding disaster occurrences specific to each area and should develop PHN training based on their disaster plans [51]. Moreover, although nearly half of the subjects (45.2\%) in this study undertook their disaster training and education, the appropriateness of the content of this training or education is still questionable. In general, appropriate disaster training and education help increase PHNs' awareness of the decision-making process; improve their understanding of the information systems; enable their use of standard operational procedures; limit inaccuracies in their treatments, triage, and documentation; and diminish insufficient training and resource shortages for future disaster events [52], [53].

However, a report from WHO found that many healthcare providers avoided engaging in their professional role and were unclear on their roles and responsibilities during the earthquake/tsunami disaster in 2004 in Aceh [32]. An evaluation of the appropriateness of the current training and disaster education programs is therefore needed [28]. The existing training courses being offered need to be further examined for content, time allocation, and training methods.

Finally, the issue of the differences in the working areas of the PHNs in this study influenced the PHNs' level of knowledge. More than half of the subjects $(59.1 \%)$ worked in an urban area in this study. Although there was no significant difference in the level of knowledge of urban PHNs and suburban/ rural PHNs, it was unexpectedly found that nurses who worked in rural areas attained higher knowledge scores (Figure 5). A study conducted by Bigbee et al. found that nurses who worked in rural or remote areas were considered less knowledgeable due to their lack of opportunity to receive formal educational preparation in public health nursing [36].

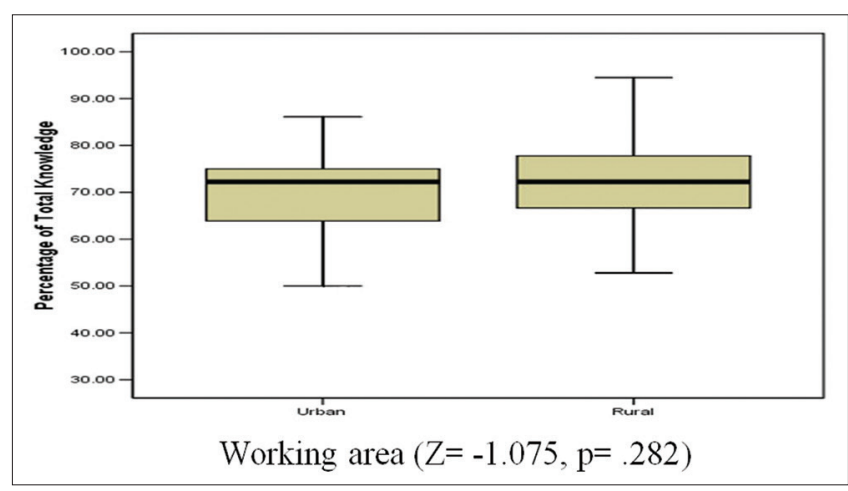

Figure 5: Box plot between working area and public health nurses knowledge (Mann-Whitney U-test) 
In this study, PHNs working in suburban/rural areas seemed to have a more excellent knowledge of disaster management than nurses in urban areas. It might be due to their perception that rural areas are at high risk of experiencing disasters. Many PHNs are interested in developing their competencies and sharpening their abilities to work effectively during future disaster events. This finding is also supported by the Transtheoretical Model of Change, which stressed that individuals motivated to reach specific achievements in life would positively impact their clinical practice areas [54]. In interpreting the above finding, one issue should also be addressed. There might be a potential sampling bias in this study concerning the distribution of the subjects, as more were from urban areas than suburban/rural areas.

The findings regarding the PHNs' knowledge of disaster management in this study must be interpreted with caution due to some methodological issues. The True/False format of the questionnaire offers a $50 \%$ chance of error from guessing. This error maybe even more significant because some subjects may fill in the questionnaire without thoughtful consideration. In addition, the researcher provided only one day to the subjects to complete the questionnaire. There is a debate between giving a long or short period, as both techniques have both pros and cons [55].

Secondly, the wording used in some question statements may confuse, such as the negative question forms used in items 18 and 26 . It may have been why most of the PHNs (83\% and $75 \%$, respectively) answered these questions incorrectly. Third, the proportion of general/basic knowledge and specific knowledge statements in each phase was not equal. Researchers assume this may have contributed to the fact that the scores for the response phase were lower than the scores for the other two phases. The questions asked in the response phase mainly dealt with particular topics; hence, the PHNs need to have the deep knowledge to answer them correctly. Regardless of the three issues identified above, the fact that a low percentage of subjects answered items 14 and 16 correctly should indeed indicate that they lacked knowledge regarding disaster triage principles. Therefore, each PHC should be given a standard operational procedure regarding vaccinations/immunizations to improve their competency in this area. Moreover, health policymakers in Aceh should routinely provide training and continuing education related to disasters, such as disaster management, basic and advanced life support, and disaster triage, to enable the nurses to attain sufficient knowledge regarding disaster management competencies.

\section{Conclusion and Recommendation}

This study found that the PHNs' knowledge of disaster management was at a moderate level.
It was supported by the level of PHNs' knowledge in three domains: a moderate level in preparedness and recovery phases and a low level in the response phase. Some factors from PHNs might influence this study's finding, including subjects' working experience, previous disaster experience in assisting disaster victims, educational background, disaster training, education, and working area.

The low level of knowledge for the response phase must be taken into detailed consideration to improve the PHNs' working in the PHCs in Aceh province. Specifically, educational training together with disaster drills regarding basic life support, disaster triage, and disaster-risk communication should be given regularly (at least once or twice a year). However, this study does not observe the details of the training programs that some subjects had received. It is recommended that the existing training programs be further explored and that the training outcomes be evaluated. Then, along with the findings of this study, more effective training programs can be established. In addition, this study found that PHNs working in suburban/rural areas may have limited accessibility to continuing education, specifically disaster management training. Hence, provision must be made to include such PHNs in future action plans.

Moreover, the limitations of the True/ False question format during data collection should be considered. Future studies should revise the knowledge questionnaire to put it into a multiple-choice format. Also, further validity and reliability testing of the questionnaires by experts in Indonesia is recommended in order to gain a better understanding of the public healthcare context of Aceh, Indonesia.

\section{Acknowledgments}

The authors gratefully thank the Director of the Institute for Research and Development on Health and Epidemiology Unit, Faculty of Medicine. Prof. Dr. Virasakdi Chongsuvivatwong, for initiating AcehSouthern Thailand Collaboration the Graduate School, Prince of Songkla University, Thailand, for partial funding to support this study. Also, thanks are extended to the Rockefeller Foundation for the corresponding author's scholarship while studying Master of Nursing Science.

\section{References}

1. Vogt V, Kulbok PA. Care of Client in Disaster Settings. Community Health Nursing: Advocacy for Population Health. 
$5^{\text {th }}$ ed. New Jersey: Pearson Prentice Hall; 2008. p. 759-800.

2. Sztajnkrycer MD, Madsen BE, Baez AA. Unstable ethical plateaus and disaster triage. Emerg Med Clin North Am. 2006;24(3):749-68. https://doi.org/10.1016/j.emc.2006.05.016 PMid:16877141

3. Her Aceh is Expected to be Able to Reduce Disaster Risk. Serambi Indonesia; 2010.

4. Ahmadi. No Deaths in Indonesia quake; Tsunami Alert Lifted; 2010. Available from: http://www.reuters.com/article/ idUSTRE6355GD20100407? [Last accessed on 2010 Apr 13].

5. Savage C, Kub J. Public health and nursing: A natural partnership. Int J Environ Res Public Health. 2009;6(11):2843-8. https://doi.org/10.3390/ijerph6112843 PMid:20049229

6. Stanley JM. Disaster competency development and integration in nursing education. Nurs Clin North Am. 2005;40(3):453-67. https://doi.org/10.1016/j.cnur.2005.04.009 PMid:16111992

7. Polivka BJ, Stanley SA, Gordon D, Taulbee K, Kieffer G, McCorkle SM. Public health nursing competencies for public health surge events. Public Health Nursing. 2008;25(2):159-65. https://doi.org/10.1111/j.1525-1446.2008.00692.x

PMid:18294184

8. Rogers B, Lawhorn E. Disaster preparedness: Occupational and environmental health professionals' response to Hurricanes Katrina and Rita. AAOHN J. 2007;55(5):197-207; quiz 208-9. https://doi.org/10.1177/216507990705500506

PMid:17526297

9. Jakeway CC, LaRosa G, Cary A, Schoenfisch S. The role of public health nurses in emergency preparedness and response: A position paper of the association of state and territorial directors of nursing. Public Health Nurs. 2008;25(4):353-61. https://doi.org/10.1111/j.1525-1446.2008.00716.x PMid:18666941

10. Jennings-Sanders A. Teaching disaster nursing by utilizing the Jennings disaster nursing management model. Nurs Educ Pract. 2004;4(1):69-76. https://doi.org/10.1016/ S1471-5953(03)00007-6

PMid:19038139

11. World Health Organization. Guidelines on Disaster Management. A Compilation of Expert Guidelines on Providing Healthcare. Sri Langka: World Health Organization; 2005.

12. Manitoba Health. Disaster Management Model for the Health Sector. Guideline for Program Development: Manitoba Health; 2000. p. 12.

13. Dinas Kesehatan Aceh. Aceh Province Health Profile 2009 Banda Aceh; 2009.

14. Singchangchai $P$, Khampalikit $S$, Na-Sae T. Nursing Research: Principle and Process. Songkhla: Tame Printing; 1996.

15. McDonald ME. Systemic Assessment of Learning Outcomes: Developing Multiple-choice Exams. Sudbury MA: Jones and Bartlett Publishers; 2002.

16. Burns N, Grove SK. The Practice of Nursing Research: Conduct, Critique, and Utilization. $5^{\text {th }}$ ed. St. Louis, Missouri: Elsevier Saunders; 2005.

17. Weiner E, Irwin M, Trangenstein P, Gordon J. Emergency preparedness curriculum in nursing schools in the United States. Nurs Educ Perspect. 2005;26(6):334-9.

PMid:16429998

18. Association of periOperative Registered Nurses. AORN guidance statement: Mass casualty, triage, and evacuation. AORN Journal. 2007;85(4):792-800. https://doi.org/10.1016/ s0001-2092(07)60154-9

PMid:17458024
19. Adams LM. Comprehensive vulnerability management: The toad to effective disaster planning with the community. J Theory Constr Testing. 2008;12:25-7.

20. Dyer CB, Regev M, Burnett J, Festa N, Cloyd B. SWiFT: A rapid triage tool for vulnerable older adults in disaster situations. Disaster medicine and public health preparedness. 2008;2(2 Suppl 1):S45-50. https://doi.org/10.1097/ DMP.0b013e3181647b81

\section{PMid:18769267}

21. Rothman M, Brown LM. The vulnerable geriatric casualty: Medical needs of frail older adults during disasters. Generations. 2007;31:16-20

22. Association of State and Territorial Directors of Nursing. Public Health Nurses' Vital Role in Emergency Preparedness and Response. Association of State and Territorial Directors of Nursing; 2002. Available from: www.astdn.org/publication_ nurses_preparedness_disaster.htm [Last accessed on 2009 Jul 20].

23. Davies K. Disaster preparedness and response: More than major incident initiation. Br J Nurs. 2005;14(16):868-71. https:// doi.org/10.12968/bjon.2005.14.16.19730 PMid:16215509

24. Kuntz SW, Frable P, Qureshi K, Strong LL. Association of community health nursing educators: Disaster preparedness white paper for community/public health nursing educators. Public Health Nurs. 2008;25(4):362-9. https://doi. org/10.1111/j.1525-1446.2008.00717.x PMid:18666942

25. Handley AJ. Basic life support. Br J Anaesth. 1997;79:151-8.

26. Liberman M, Mulder D, Sampalis J. Advanced or basic life support for trauma: Meta-analysis and critical review of the literature. J Trauma. 2000;49(4):584-99. https://doi. org/10.1097/00005373-200010000-00003

PMid: 11038074

27. Mitani S, Kuboyama K, Shirakawa T. Nursing in sudden-onset disasters: Factors and information that affect participation. Prehosp Disaster Med. 2003;18(4):359-66; discussion 365-6. https://doi.org/10.1017/s1049023×00001321 PMid:15310049

28. De Felice M, Giuliani AR, Alfonsi G, Mosca G, Fabiani L. Survey of nursing knowledge on bioterrorism. Int Emerg Nurs. 2008;16(2):101-8. https://doi.org/10.1016/j.ienj.2008.01.004 PMid:18519061

29. Kimmel SR, Burns IT, Wolfe RM, Zimmerman RK. Addressing immunization barriers, benefits, and risks. J Fam Pract. 2007;56(2 Suppl Vaccines):S127-35.

\section{PMid:17270112}

30. Maulidar. A Comparative Study of Knowledge and Perceived Skills Regarding Tsunami Disaster Nursing during Recovery Phase between Public Health Nurses Working in Tsunami Affected and Non-affected Area in Aceh Province, Indonesia. Hatyai: Prince of Songkla University; 2011.

31. Hennessy D, Hicks C, Hilan A, Kawonal Y. A methodology for assessing the professional development needs of nurses and midwives in Indonesia: Paper 1 of 3 . Hum Resour Health. 2006;4:1-8. https://doi.org/10.1186/1478-4491-4-8 PMid:16623935

32. World Health Organization. The Contribution of Nursing and Midwifery in Emergencies. Geneva: World Health Organization; 2006.

33. Hammad KS, Arbon P, Gebbie KM. Emergency nurses and disaster response: An exploration of South Australian emergency nurses' knowledge and perceptions of their roles in disaster response. Aust Emerg Nurs J. 2010;14(2):87-94. https://doi.org/10.1016/j.aenj.2010.10.002 
34. Burstein JL. The myths of disaster education. Ann Emerg Med. 2006;47(1):50-2. https://doi.org/10.1016/j. annemergmed.2005.11.023

PMid:16387218

35. Arbon P. Understanding experience in nursing. J Clin Nurs 2004;13(2):150-7. https://doi.org/10.1046/j.1365-2702.2003.00861.x PMid:14723666

36. Bigbee JL, Otterness N, Gehrke P. Public health nursing competency in a rural/frontier state. Public Health Nurs. 2010;27(3):270-6. https://doi. org/10.1111/j.1525-1446.2010.00853.x PMid:20525100

37. Chan MF. A cluster analysis to investigate nurses' knowledge, attitudes, and skills regarding the clinical management system. Comput Inf Nurs. 2007;25:45-54.

38. Lia-Hoagberg B, Schaffer M, Strohschein S. Public health nursing practice guidelines: An evalution of dissemination and use. Public Health Nurs. 1999;16(6):397-404. https://doi. org/10.1046/j.1525-1446.1999.00397.x

PMid:10620249

39. Gebbie KM, Qureshi K. Emergency and disaster preparedness: Core competencies for nurses: What every nurse should but may not know. Am J Nurs. 2002;102(1):46-51. https://doi. org/10.1097/00000446-200201000-00023 PMid:11839908

40. Duong K. Disaster education and training of emergency nurses in South Australia. Aust Emerg Nurs J. 2009;12(3):86-92. https:// doi.org/10.1016/j.aenj.2009.05.001

41. Shields L, Hartati LE. Nursing and health care in Indonesia. J Adv Nurs. 2003;44(2):209-16. https://doi. org/10.1046/j.1365-2648.2003.02785.x

42. Carlisle C, Luker KA, Davies C, Stilwell J, Wilson R. Skills competency in nurse education: Nurse managers' perceptions of diploma level preparation. J Adv Nurs. 1999;29(5):1256-64. https://doi.org/10.1046/j.1365-2648.1999.01011.x PMid:10320511

43. Saha D. Improving Indonesian Nursing Students' Self-directed Learning Readiness. Queensland: Queensland University of Technology; 2006.

44. Pusdiknakes. Nationally Applicable Curriculum for Nursing Diploma III Program. Jakarta: Ministry of Education and Culture; 1999. Available from: http://www.pusdiknakes. or.id/?show=data/kurikulum/kurikulum_akper [Last accessecd on 2011 Mar 15]
45. Asosiasi Institusi Pendidikan Ners Indonesia. Nursing Curriculum. Jakarta: Asosiasi Institusi Pendidikan Ners Indonesia; 2008. Available from: http://aipni.blogspot.com/p/ nursing-curriculum.html [Last accessed on 2011 Jan 11].

46. Nazar M. Aceh Pioneer of Disaster Nursing Education. Banda Aceh; 2009. Available from: http://koran.republika.co.id/ berita/53667/aceh_pioner_pendidikan_keperawatan_bencana [Last accessed on $2011 \mathrm{Feb}$ 07].

47. Yamamoto A. Education and research on disaster nursing in Japan. Prehosp Disaster Med. 2008;23(3):s6-7.

PMid:18702281

48. Chapman K, Arbon P. Are nurses ready? Disaster preparedness in the acute setting. Aust Emerg Nurs J. 2008;11:135-44.

49. Jennings-Sanders A, Frisch N, Wing S. Nursing students perceptions about disaster nursing. Disaster Manag Response. 2005;3(3):80-5. https://doi.org/10.1016/j.dmr.2005.04.001 PMid:15986028

50. Fung OW, Loke AY, Lai CK. Disaster preparedness among Hongkong nurses. J Adv Nurs. 2008;62(6):698-703. https://doi. org/10.1111/j.1365-2648.2008.04655.x PMid:18503654

51. Nur L. An Overview of the Preparedness of Puskesmas Nurses in Disaster Management at Kasihan I Puskesmas Bantul. Yogyakarta: IImu Keperawatan; 2010.

52. Edwards NA, Caldicott DG, Eliseo T, Pearce A. Truth hurts hard lessons from Australia's largest mass casualty exercise with contaminated patients. Emerg Med Aust. 2006;18(2):185-95. https://doi.org/10.1111/j.1742-6723.2006.00827.x PMid:16669945

53. Henderson DA, Inglesby TV, O'Toole T, Grossman R. A plague on your city: Observations from TOPOFF. Clin Infect Dis. 2001;32(3):436-45. https://doi.org/10.1086/318513 PMid:11170952

54. Melnyk BM, Fineout-Overholt $\mathrm{E}$, Fischbeck Feinstein $\mathrm{N}$ Li H, Small L, Wilcox L, et al. Nurses' perceived knowledge, beliefs, skills, and needs regarding evidence-based practice: Implications for accelerating the paradigm shift. Worldviews Evid Based Nurs. 2004;1(3):185-93. https://doi. org/10.1111/j.1524-475X.2004.04024.X PMid:17163896

55. Carey MP, Morrison-Beedy D, Johnson BT. The HIV-Knowledge questionnaire: Development and evaluation of a reliable, valid and practical self-administered questionnaire. AIDS Behav. 1997;1:61-74. 